\title{
Modification of cognitive behavior therapy to improve the skill of elderly with osteoarthritis
}

\author{
Rizkiyani Istifada ${ }^{1 *}$, Etty Rekawati ${ }^{2}$, and Widyatuti ${ }^{2}$ \\ ${ }^{1}$ Department of Nursing, Faculty of Health, Universitas Muhammadiyah Tangerang, Tangerang, Indonesia \\ ${ }^{2}$ Department of Community Health Nursing, Faculty of Nursing, Universitas Indonesia, Depok, Indonesia
}

\section{KEYWORDS}

Cognitive behavioral therapy

Community health nurse

Elderly

Osteoarthritis

Self-management
ABSTRACT One of the characteristics of physical changes in the elderly involves a decrease in the musculoskeletal system, such as the depletion of the synovial joint fluid which has an impact on the pain felt in joints. This condition can cause a disruption of the quality of life for the elderly and results in increases in the family burden. The purpose of cognitive behavioral therapy in nurse care planning is to provide an overview of the implementation of family care nursing, community care health nursing, and management of health services by community health nurses to the elderly with osteoarthritis. The innovation and development of this senior citizen community program, initially named Lansia SMART (SMART Elderly), consists of six sessions, including psychoeducation sessions, cognitive restructuring sessions, pain management sessions with progressive muscle relaxation, activity scheduling sessions, problem-solving sessions, and tutorial sessions for the Lansia SMART (SMART Elderly) group with the Android application. The final maintaining challenging stage of these services involved 59 elderly participants. Data analysis used paired T-tests. The results of this innovation showed significant differences in the behavior of the elderly participants after the implementation of the SMART Elderly program $(p<0.05)$. The SMART Elderly program was effective to improve the elderly participants' behavior. Nurses can use cognitive behavioral therapy to improve the process of self-management of osteoarthritis among their clients.

(c) The Journal 2021. This article is distributed under a Creative Commons Attribution-ShareAlike 4.0 International license.

\section{Introduction}

The elderly experience an aging process biologically that causes a decrease in their immune response, which has an impact on their vulnerability of developing an illness. Degenerative diseases are some of the most common illnesses faced by the elderly due to their decreased immune system. Hypertension, arthritis, and stroke contribute the three most common degenerative diseases based on the results of the Basic Health Research. ${ }^{1}$ Osteoarthritis disease can cause pain, stiffness, and mobility problems, thereby affecting psychological and social conditions. ${ }^{2,3}$ The symptoms are generally characterized by a continuous pain response from the sufferer. ${ }^{4}$ This pain can cause obstacles to mobilization

\footnotetext{
*Correspondence: rizkiyani.istifada@gmail.com Department of Nursing, Faculty of Health, Universitas Muhammadiyah Tangerang, Jl. Perintis Kemerdekaan 1, Tangerang, 15118, Indonesia
}

and disruption in the basic needs of the elderly. The changes of function have an impact on the structure of the body. ${ }^{5}$ Based on the Basic Health Research report, the elderly have a level of dependence due to joint disease, with the categories of mild dependence (28.44\%), moderate dependence (1.52\%), severe dependence (1.13\%), and total dependence (1.46\%). ${ }^{6}$ The existence of this level of dependence risks also is causing a high economic burden.

The joint disease problems are the second largest of the non-communicable disease (NCD) prevalence in Depok City, amounting to 44,628 cases. $^{7}$ The incidence rate in Depok City showed an increase in cases of joint disease from 2016 to 2017, which changed from $4.26 \%$ to $4.68 \%{ }^{7,8}$ Osteoarthritis is one of the joint illnesses in the elderly. Osteoarthritis is a degenerative disease caused by damage to joints in the cartilage, causing pain and functional impairment. ${ }^{9}$ Osteoarthritis can cause a disturbance in the quality of life of the elderly. ${ }^{10}$ If not treated, 
osteoarthritis problems can interfere with the quality of life and productivity of the elderly. ${ }^{11}$

Self-management is one intervention that focuses on cognitive-behavioral changes. ${ }^{12}$ Cognitivebehavioral therapy can be used to improve selfmanagement. The cognitive-behavioral approach is designed to help someone who has a problem by recognizing, evaluating, and correcting maladaptive conceptualizations. ${ }^{13}$ Understanding and recognizing can improve self-management to change maladaptive behavior to more adaptive responses. The way to deal with the negative emotions caused by pain is to accept the problem's presence. ${ }^{14}$ This therapeutic model approach is also effective in dealing with chronic pain that is often felt by the elderly with osteoarthritis. Some research results explain that cognitive-behavioral therapy changes the pain which comes from thoughts, emotions, and behavior using relaxation activities, cognitive restructuring, and problem-solving. ${ }^{15,16}$ The elderly with chronic pain are educated to recognize the pain with cognition, affect, and behavior related to the consequences that follow. ${ }^{16}$ This treatment can change beliefs about pain, coping with pain, and skills/control over pain using pain management. It can be interpreted that the impact of a cognitive behavioral therapy approach can improve self-management of osteoarthritis disease.

The effectiveness of the psychosocial approach is used as a guideline in the implementation of osteoarthritis self-management. The implementation of this intervention is named the SMART Elderly program that is focused on increasing knowledge of osteoarthritis problems of the elderly, pain management skills, and their treatment. Therapy sessions with a cognitive-behavioral approach can help to treat osteoarthritis pain. ${ }^{15}$ This finding is similar to several studies that showed the cognitive behavioral therapy was effective to reduce the scale of osteoarthritis pain in the elderly. ${ }^{17}$ In general, this cognitive behavioral therapy session consists of goal setting, relaxation, activity scheduling, cognitive restructuring, problem-solving, and maintaining changes. ${ }^{15}$ Based on the therapy session, the implementation of this community service is expected to improve the skills of the elderly in overcoming joint pain.

\section{Method}

\subsection{Design}

This community service used quasi-experimental quantitative methods with the implementation of training and health education. The evaluation used the level of pain based on the WOMAC index pain subscale. ${ }^{18}$ Because the instruments of evaluation used are standardized and have been used by previous studies, there were no validity and reliability tests. The WOMAC instrument has a validity value ranging from 0.48 to $0.53(p>0.05)$ and a reliability value of $0.9(p>0.85) .{ }^{18}$ The implementation of this intervention used the elderly skill level instrument before/after the intervention. The reliability test was done because it was modified from previous research. ${ }^{19}$ The results of the instrument test on 39 respondents showed a reliability value of 0.89 . Measurement of skills includes recognizing problems, deciding on treatment, monitoring self-activity, and solving the problems in using non-pharmacological pain management, such as exercise and relaxation. Data analysis used the paired T-test which is used as a comparative hypothesis for numerical variables.

\subsection{Participants}

The program involved 59 elderlies in Mekarjaya Village, Depok City. The sample inclusion criteria included: (1) elderly with osteoarthritis problems, and (2) willingness to participate in intervention activities. The selection of participants used the purposive sampling technique.

\subsection{Data Collection}

This community service implementation is called SMART Elderly (Healthy with Osteoarthritis SelfManagement) and used the Cognitive Behavior Therapy approach. The implementation was conducted by nurses (Master's students) who are completing the study of Community Health Nursing Specialist. In addition, Nursing Interventions Classification (NIC) explains that the implementation of Cognitive Behavior Therapy can be done by postbasic nurses (graduates of master). ${ }^{20}$ Based on this, the implementation of this therapy has been done by competent nurses following the established criteria. 
The cognitive-behavioral therapy sessions consist of $6-12$ sessions. ${ }^{15,18}$

Based on these various studies, the community service program consists of six sessions in 6 months. In the first session, the intervention was a psychoeducational activity by explaining the factors of osteoarthritis (OA), early signs, and symptoms of the disease, the benefits of disease management, and pain management strategies. The first session was conducted for 60 minutes, using the group process method.

The second session used the cognitive restructuring method. This technique aims to determine the commitment to transform negative actions into adaptive efforts in self-management of osteoarthritis. The elderly used an instrument sheet to identify their problem. In the third session, the elderly practice progressive muscle relaxation techniques to treat joint pain. In this session, the elderly did relaxation exercises by involving the hands and arms, dominant biceps, neck, shoulders, calves, and legs.

In the fourth session, the elderly did activity scheduling by filling out the pain monitoring journal while in the fifth session, the problem-solving stage used behavior cards in the simulation of problemsolving. At the final stage of intervention, the elderly were given an evaluation of the implementation of osteoarthritis self-management, which is called the maintaining challenging stage.

\section{Result}

The measuring of evaluations used the WOMAC instrument and the self-management of elderly skills instrument. The pain results after intervention are illustrated in Table 1. It shows a decrease in the percentage of pain scale in the elderly after being given the SMART Elderly intervention. Before the intervention, most of the elderly had a mild joint pain scale category. There was a decrease in the number of moderate and severe scale categories after being given the SMART Elderly intervention, namely the scale category before the intervention changed from a percentage of $12 \%$ to $5 \%$.

After doing the parameter test, two variables also have data which are normally distributed (sig $>0.05$ ). The number of participants involved in this intervention were 59 elderlies, so the normal data analysis used Kolmogorov-Smirnov (Table 2). Therefore, the analysis used is a comparative hypothesis test of numerical variables in two paired groups. The paired T-test resulted in a significance value of $0.001(p<0.05)$, which means "there is a significant difference of the skills in elderly before and after the SMART Elderly intervention". Evaluation of the skills scores in the elderly after being given the intervention showed an increase in the mean skills (Table 3 ). There were two elderly who did not attend the session in 2 times, so these dropped out of this intervention. Despite the drop out, the number of samples involved is representative based on the sample calculation. The innovation aimed to overcome the limitations of implementing osteoarthritis self-management. The application provides information about osteoarthritis and a healthy menu to diet.

The elderly identified their level of knowledge about the causes of osteoarthritis and the initial symptoms. The group also identified the impact if they were not resolved, and various treatment in osteoarthritis management. In the results from the first session, most of the elderly can recognize the causes, signs, and symptoms of osteoarthritis and the consequences if there is no treatment (Figure 1a). In the second session, the elderly were also assisted using picture cards when dealing with joint pain. After identifying their behavior, the elderly practiced to determine their commitment and a behavior change plan in their pain monitoring journal (Figure 1b).

In the problem-solving session, nurses provided stimulus to the elderly by various case studies to solve

Table 1. Distribution of elderly pain scale categories before and after intervention SMART elderly $(n=59$ people)

\begin{tabular}{lllll}
\hline & Mild (\%) & Moderate (\%) & Severe (\%) & Very Severe (\%) \\
\hline Pre-intervention & 68 & 20 & 12 & 0 \\
\hline Post-intervention & 77 & 18 & 5 & 0 \\
\hline
\end{tabular}


Table 2. Test of normality of elderly skill ( $n=59$ people)

\begin{tabular}{lll}
\hline Variable & Sig, Kolmogorov-Smirnov & Sig. Shapiro-Wilk \\
\hline Elderly Skill & 0.200 & 0.505 \\
\hline
\end{tabular}

Table 3. Analysis of Elderly Skill Before \& after intervention SMART elderly ( $n=59$ people)

\begin{tabular}{llll}
\hline Variable & Mean & SD & $p$ Value \\
\hline Pre-intervention & 8.9831 & 2.58971 & \multirow{2}{*}{0.001} \\
\hline Post-intervention & 10.7797 & 2.49183 & \\
\hline
\end{tabular}

problems in treating joint pain (Figure 2). If the elderly had been able to complete the case management, the elderly can independently determine joint pain treatment. In the sixth session, the elderly did the tutorial stage of the SMART Elderly application with a smartphone (Figure 3 ). In this session, community health workers were trained to monitor once a month in Posbindu. This application was used to monitor and maintenance challenging stages the self-management of the elderly by using a screening examination of the level of physical activity, the level of pain monitoring, and the need for calories to determine dietary implementation, especially in the elderly who are overweight.

\section{Discussion}

In the first session of the SMART Elderly program, psychoeducation could increase understanding about osteoarthritis more clearly. In this session, the elderly were informed about the treatments. Psychoeducation is an intervention by integrating psychotherapeutic and education to improve the acceptance of the disease from the client, increase client participation in therapy, and develop coping mechanisms. ${ }^{22}$ Intervention with psychoeducation can improve the ability to manage pain. ${ }^{23}$ The impact of using picture cards shows an increase in knowledge level. This method makes it easier for the elderly to understand the explanation of osteoarthritis material. Psychoeducation using a picture card has also been conducted by several studies in the implementation. ${ }^{24}$ The results of the intervention also showed an increase in the level of knowledge of respondents who attended psychoeducation.

In the second session, the elderly can make decisions by engaging in selected self-management adaptive behaviors, such as eating healthy foods, not doing strenuous activities, not lifting heavy objects, and engaging in physical activity. Cognitive restructuring techniques can build coping mechanism to manage pain intensity in osteoarthritis. ${ }^{25}$ Based on this research, the approach describes one of the factors for improving skills because of the cognitive restructuring techniques in the SMART Elderly innovation program. The identifying problems were influenced by cognitive and emotional factors to form these subjective pain perceptions and responses. Based on this, the decisions do not only focus on the knowledge they have but also the need for social and environmental support that influence each other. Social and family support can change the behavior of the elderly in disease control. ${ }^{26}$ It can form an adaptive response when older people identify problems with pain.

In the third session, the elderly did a relaxation technique to overcome or prevent pain, namely by progressive muscle relaxation. The study also explained that progressive muscle relaxation was one session in the cognitive-behavioral therapy to improve pain management. ${ }^{15} \mathrm{~A}$ progressive muscle relaxation showed a significant result in coping strategies when the elderly feel pain. ${ }^{27}$ The evaluation results showed an increase of the percentage in WOMAC scoring in the low category after the intervention. A progressive muscle relaxation technique is one of the coping strategies to reduce the scale of joint pain.

In the fourth session, the elderly wrote about their behavior in an activity journal. In this intervention, the elderly practiced their skill management so that the elderly could prevent pain. The evaluation showed that not all elderly fill in the monitoring journal regularly. No significant 


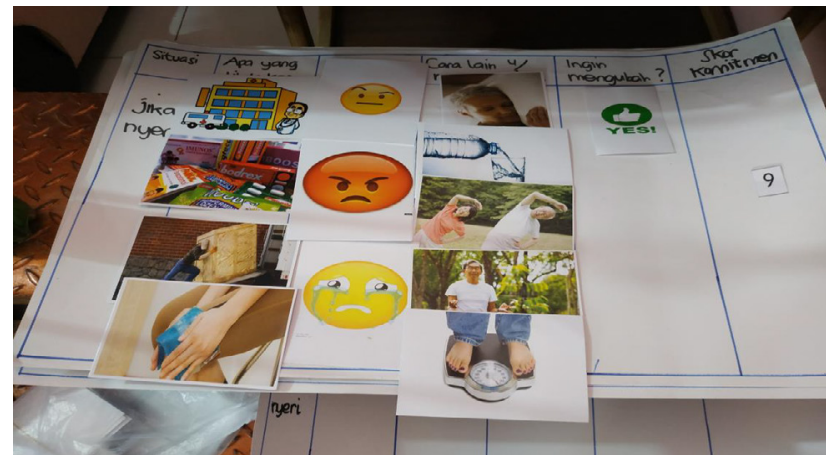

(a)

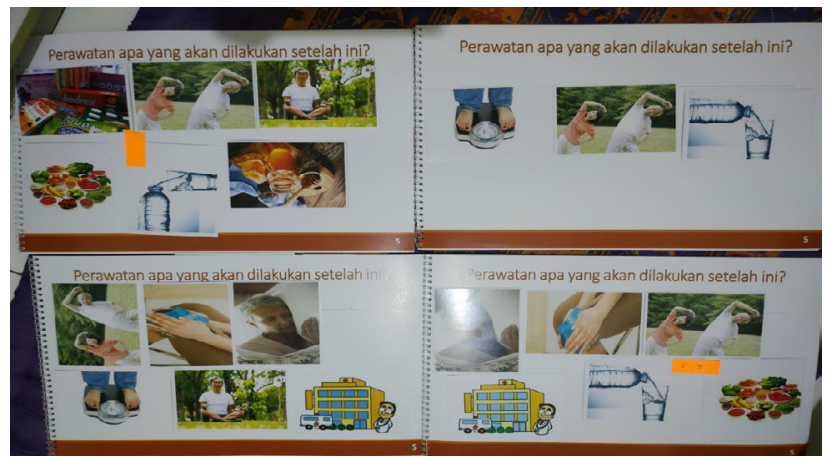

(b)

Figure 1. (a) Elderly's skill to identify the health problem with picture card in the psychoeducation session; and (b) Cognitive restructuring with picture card to assign the elderly commitment into adaptive behavior.
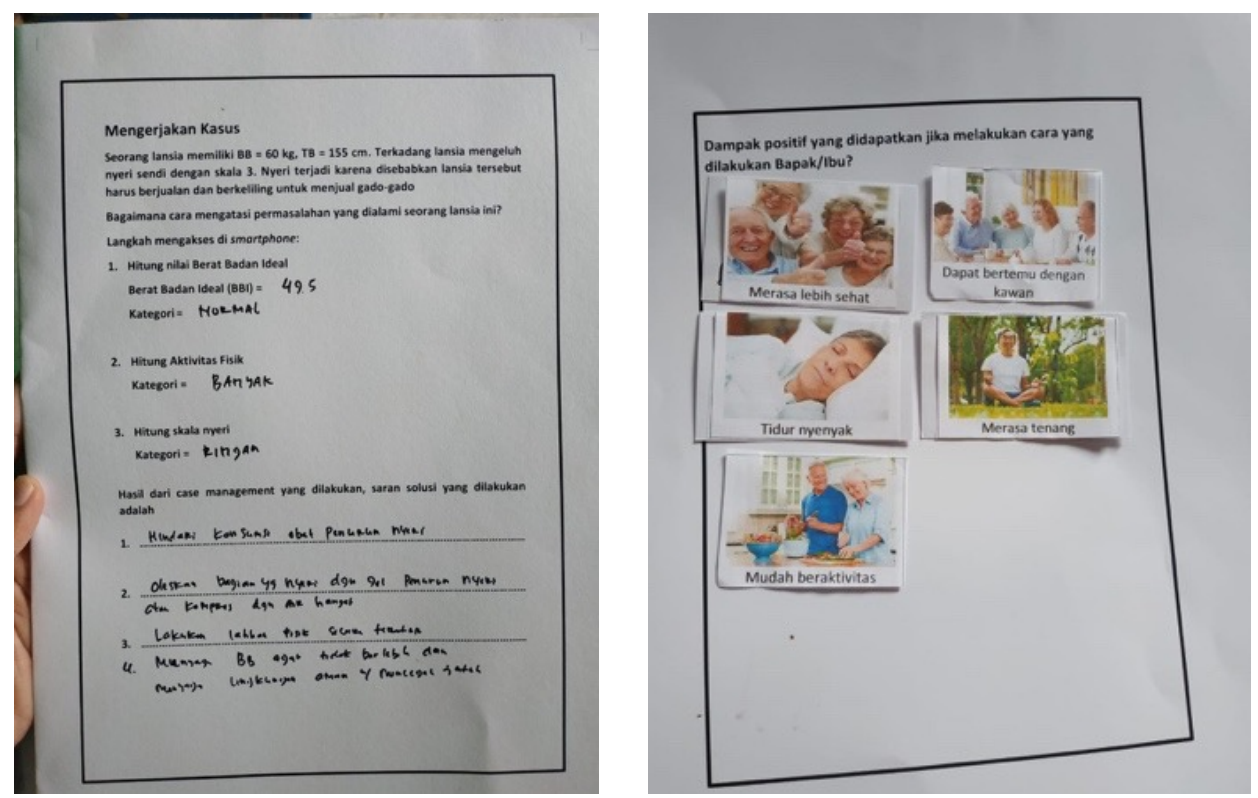

Figure 2. The results of problem-solving determined by the elderly to deal with pain

differences occurred in the group using the journal to monitor pain. ${ }^{28}$ The implementation of monitoring using journals can be successful if it is followed up to 1.5 years. ${ }^{29}$ To solve this problem, the researchers compiled other innovative media by developing Android applications as a process in carrying out continuous monitoring. The use of mobile health can facilitate self-management monitoring in the elderly..$^{30}$

In the fifth session, the activities done were problem-solving sessions. It was part of the stages of cognitive-behavioral therapy. These techniques generally involve the process of identifying someone with effective ways to solve problems, one of which is pain problems. ${ }^{31}$ The implementation of problemsolving sessions used the case management method. The elderly group should answer several questions in the form of cases with osteoarthritis problems. The ability of the elderly to answer the case questions shows that the elderly group can recognize the problems as an effort to control their disease. Problem-solving techniques teach a person specific skills to increase control over problems that are difficult to control. At this stage, a person learns about problem solving, so that efforts to implement self-management become more optimal. This is also indicated by an increase in self-efficacy in the elderly group after being given the intervention. The results 




(a)

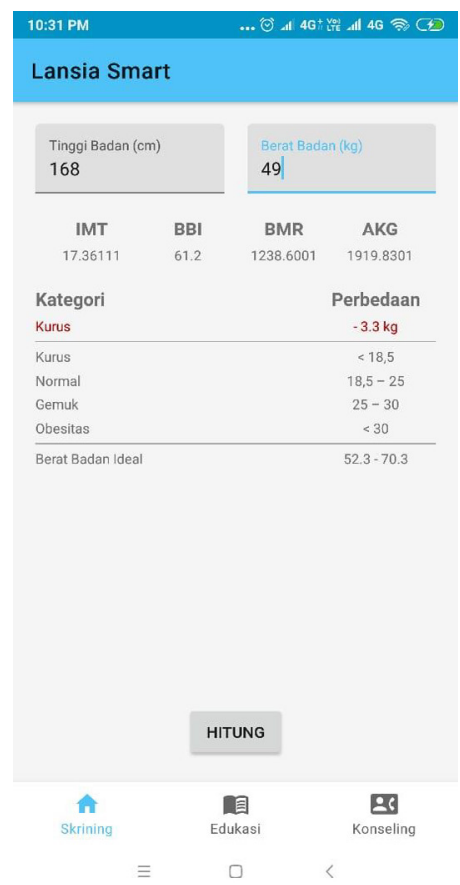

(b)



(c)

Figure 3. Elderly SMART Application in Smartphone (a) dashboard of main menu in an application; (b) calculation menu of calorie needs; and (c) calculation menu of pain scale.

also confirmed that there was an increase in skills and confidence in the interventions taught after being given the behavior therapy. ${ }^{32}$

In the sixth session, the elderly group was given an application tutorial as a medium to support the implementation of osteoarthritis self-management monitoring. This is a program to overcome the limitations of self-monitoring using daily journals. Monitoring using the Internet technology can improve coping mechanisms for pain. ${ }^{33}$ Based on the evaluation, the elderly have adapted to the joint pain problems caused by osteoarthritis by taking regular breaks or doing light activities. This concept is one of the ways the elderly group responds to pain. The factors in this approach are how individuals learn to adapt to the pain based on their experiences.

The results after implementing the innovation showed a decrease in the pain scale. Cognitivebehavioral therapy interventions are effective in reducing the degree of osteoarthritis pain in the elderly. ${ }^{17,34}$ The results also showed an increase in the skills of the elderly in osteoarthritis management. The increasing of knowledge affects the elderly in increasing their coping abilities. When clients understand the signs and symptoms, they generally know the actions taken in osteoarthritis management. ${ }^{35}$ Based on this, the implementation of education can increase skill levels.

The success of the SMART Elderly program is also due to the optimal role of community health workers in conducting these activities routinely in their environment. One of the supports by community health workers was when they explained to the elderly about the benefits of participating in this intervention. The involvement of community health workers to assist in self-management can improve healthy living behavior. ${ }^{36}$ The SMART Elderly program can be done independently by the elderly, so that this intervention process can support the implementation of health services, especially at the primary level. This innovation can be a modified reference for public health care and family nursing care in improving osteoarthritis self-management.

This intervention has some limitations when implementing self-monitoring using a smartphone application. The characteristics of the elderly in Indonesia are that some are not exposed to access to smartphones. They think that smartphone access 
is not a need that must be understood and owned by the elderly. That is a challenge in implementing the Android-based application innovations (Elderly SMART). This condition causes the commitment to complete the self-monitoring using a smartphone to be not optimal. Therefore, the research team provided video tutorials for operating the SMART Elderly application to families. Most of the respondent's families were involved in filling out the osteoarthritis self-management monitoring in this application, so the monitoring process continues. The support provided by the family can improve the health condition of the elderly at home. ${ }^{37}$

\section{Conclusions}

The phenomenon of osteoarthritis occurring in the elderly is still increasing. The cognitive behavioral therapy approach carried out in community service activities is not a substitute therapy for pharmacological health care. This program session is a complementary intervention to reduce pain sensations. The management of chronic pain is still limited to drug therapy. Psychological pain management is still not a commonly used form of therapy. This treatment can be done independently by the elderly and their families. Health workers and the community should collaborate in reducing the impact that occurs due to osteoarthritis.

\section{Acknowledgments}

Thanks to Yayasan Baitul Maal (YBM PLN) who provided the funding.

\section{Conflict of interests}

The authors declare no conflict of interest.

\section{References}

1. Badan Penelitian dan Pengembangan Kesehatan. Riset Kesehatan Dasar (RISKESDAS) 2013. Lap Nas 2013. 2013;1-384.

2. Miller CA. Nursing Wellness in Older Adults. 6th edition, editor. Philadelphia: Lippincott Williams \& Wilkins; 2012.
3. Allender JA, Rector C, Kristine D. Warner. Community \& Public Health Nursing: Essentials of Nursing Research, 8th Ed. Handbook Promoting the Public's Health. Lippincott Williams \& Wilkins; 2015.

4. Woolf AD, Pfleger B. Burden of major musculoskeletal conditions. Bulletin of the World Health Organization. 2003.

5. Allender JA, Rector C, Warner K. Community Health Nursing: Promoting \& Protecting the Public's Health. Vol. 136, Journal of Experimental Psychology: General. Philadelphia: Lippincott Williams \& Wilkins; 2010. 23-42 p.

6. Kementerian Kesehatan RI. Hasil Utama Riskesdas Tahun 2018. 2018.

7. Dinas Kesehatan Kota Depok. Profil Kesehatan Kota Depok Tahun 2017. Depok; 2018.

8. Dinkes Kota Depok. Dinas Kesehatan Kota Depok. Profil Dinas Kesehat Kota Depok Tahun 2016 [Internet]. 2016;187:164. Available from: http://dinkes.depok.go.id/

9. Ferreira RL de AM, Duarte JA, Gonçalves RS. Nonpharmacological and non-surgical interventions to manage patients with knee osteoarthritis: An umbrella review. Acta Reumatol Port. 2018;2018(3):182-200.

10. Törmälehto $S$, Aarnio $E$, Mononen $M E$, Arokoski JPA, Korhonen RK, Martikainen JA. Eightyear trajectories of changes in health-related quality of life in knee osteoarthritis: Data from the Osteoarthritis Initiative (OAI). PLoS One. 2019;14(7):1-17.

11. Mahir L, Belhaj K, Zahi S, Azanmasso H, Lmidmani F, El Fatimi A. Impact of knee osteoarthritis on the quality of life. Ann Phys Rehabil Med [Internet]. 2016;59(2016):e159. Available from: http://dx.doi.org/10.1016/j.rehab.2016.07.355.

12. Lorig KR, Holman HR. Self-management education: History, definition, outcomes, and mechanisms. Annals of Behavioral Medicine. 2003 Aug;26(1):1-7.

13. Cakrangadinata. Penerapan Terapi dengan Pendekatan Cognitive- Behavioral dalam Penanganan Nyeri pada Pasien Nyeri Kronik. J Pemikir Penelit Psikol. 2016;11(1):1-10.

14. Hanum L. Manajemen nyeri untuk meningkatkan 
penerimaan nyeri kronis pada lansia dengan intervensi multi-komponen kelompok cognitive behavior therapy (CBT). 2012. Tesis Fakultas Psikologi. Universitas Indonesia. Jakarta.

15. Keefe FJ, Porter L, Somers T, Shelby R, Wren A V. Psychosocial interventions for managing pain in older adults: Outcomes and clinical implications. Br J Anaesth. 2013;111(1):89-94.

16. Pu L, Moyle W, Jones C, Todorovic M. Psychosocial interventions for pain management in older adults with dementia: A systematic review of randomized controlled trials. J Adv Nurs. 2019;75:1608-20.

17. Vitiello $M V$, McCurry SM, Shortreed SM, Balderson BH, Baker LD, Keefe FJ, et al. Cognitivebehavioral treatment for comorbid insomnia and osteoarthritis pain in primary care: The lifestyles randomized controlled trial. J Am Geriatr Soc. 2013;61(6):947-56.

18. Soininen J V, Paavolainen PO, Gronblad MA, Kaapa EH. Validation study of a Finnish version of the Western Ontario and McMasters University osteoarthritis index. HIP Int. 2008;18(2):108-11.

19. Yuliharni S. Implementation of community nursing intervention coaching diet and exercise to decrease pain level of joint desease in elderly aggregate in Srengseng Sawah. Tesis. Universitas Indonesia; 2016.

20. Bulechek GM, Butcher H, Dochterman J, Wagner C. Nursing Interventions Classification (NIC). 6th Edition. Singapore: Mosby, Elsevier Inc.; 2016.

21. Pitsillides A, Stasinopoulos D, Giannakou K. The effects of cognitive behavioural therapy delivered by physical therapists in knee osteoarthritis pain: A systematic review and meta-analysis of randomized controlled trials. J Bodyw Mov Ther [Internet]. 2021;25(November):157-64. Available from: https://doi.org/10.1016/j. jbmt.2020.11.002

22. Smith D, Jones I, Simpson S. Psychoeducation for bipolar disorder. Advances in Psychiatric Treatment. 2010.

23. Ismail A, Moore C, Alshishani N, Yaseen K, Alshehri MA. Cognitive behavioural therapy and pain coping skills training for osteoarthritis knee pain management: A systematic review. J Phys Ther Sci. 2017;29(12):2228-35.
24. Machmudah. The effectiveness of the psychoeducation toilet training with demonstration video and card picture toward increasing mother's knowledge and ability to toilet training toddler in informal. 2016;

25. Astuti I, Rosani D, Tuapattinaja JMR. Effectiveness of group cognitive behavioral therapy for decreasing pain intensity in osteoarthritis patients. 2019;4(1):125-7.

26. Thaniwattananon $P$, Sinaga $F$. The effect of a group support enhancing self-management program on lifestyle modification behaviors among Indonesian older adults with knee osteoarthritis. Walailak J Sci Technol. 2019;16(8):593-600.

27. Janevic $M$, Robinson-Lane SG, Murphy SL, Courser R PJ. A pilot study of a chronic pain selfmanagement program delivered by community health workers to underserved African American older adults. Pain Med. 2021; 29;pnaa468.

28. GreenSM, Hadjistavropoulos T, Hadjistavropoulos $H$, Martin R, Sharpe D. A controlled investigation of a cognitive behavioural pain management program for older adults. Behav Cogn Psychother. 2009;37(2):221-6.

29. Forman EM, Shaw JA, Goetter EM, Herbert JD, Park JA, Yuen EK. Long-term follow-up of a randomized controlled trial comparing acceptance and commitment therapy and standard cognitive behavior therapy for anxiety and depression. Behav Ther. 2012; Dec;43(4):801-11.

30. Kuerbis A, Mulliken A, Muench F, A. Moore A, Gardner D. Older adults and mobile technology: Factors that enhance and inhibit utilization in the context of behavioral health. Ment Heal Addict Res. 2017;2(2).

31. Swensen K, Voss $M$, Condie A, Yaugher A. Cognitive behavioral therapies for the management of chronic pain. All Curr Publ [Internet]. 2020;(August). Available from: https://digitalcommons.usu.edu/extension_ curall/2128

32. Ehde DM, Dillworth TM, Turner JA. Cognitivebehavioral therapy for individuals with chronic pain: Efficacy, innovations, and directions for research. Am Psychol. 2014;69(2):153-66.

33. Bennell KL, Nelligan R, Dobson F, Rini C, Keefe 
F, Kasza J, et al. Effectiveness of an internetdelivered exercise and pain-coping skills training intervention for persons with chronic knee pain: A randomized trial. Ann Intern Med. 2017 Apr 4;166(7):453-462.

34. Hatefi M, Parvizi R, Borji M, Tarjoman A. Effect of self-management program on pain and disability index in elderly men with osteoarthritis. Anesthesiol Pain Med. 2019;9(4).

35. Kao MH, Tsai YF. Clinical effectiveness of a selfregulation theory-based self-management intervention for adults with knee osteoarthritis: A long-term follow-up. J Nurs Scholarsh. 2020;52:643-51.

36. Istifada R, Rekawati E. Peran Kader Kesehatan dalam Promosi Pencegahan Komplikasi Hipertensi di Wilayah Perkotaan: Literatur Review. Dunia Keperawatan. 2019;7(1):28-46.

37. Rekawati E, Istifada R, Sari NLPDY. Perceptions of family caregivers on the implementation of the cordial older family nursing model: A qualitative study. Enferm Clin. 2019;29:211-8. 